\title{
Diffuse large B cell lymphoma derived from nodular lymphocyte predominant Hodgkin lymphoma presents with variable histopathology
}

\author{
Sylvia Hartmann ${ }^{1 *}$, Mine Eray ${ }^{2}$, Claudia Döring ${ }^{1}$, Tuula Lehtinen ${ }^{3}$, Uta Brunnberg$^{4}$, Paula Kujala ${ }^{2}$,
} Martine Vornanen ${ }^{2+}$ and Martin-Leo Hansmann ${ }^{1+}$

\begin{abstract}
Background: Nodular lymphocyte predominant Hodgkin lymphoma (NLPHL) usually presents in middle aged men and shows an indolent clinical behavior. However, up to 30\% of the patients present a secondary transformation into aggressive diffuse large $B$ cell lymphoma (DLBCL). The aim of the present study was to characterize morphology and immunophenotype of this kind of DLBCL in detail and compare it with conventional DLBCL.

Methods: Morphology and immunophenotype of 33 cases of NLPHL with simultaneous or sequential transformation into DLBCL were investigated. These cases were compared with 41 de novo DLBCL in Finnish men.

Results: The majority of cases exhibited different immunophenotypes in the NLPHL and the DLBCL components. The immunophenotype of the DLBCL secondary to NLPHL was heterogeneous. However, BCL6, EMA, CD75 and J-chain were usually expressed in both components ( $\geq 73 \%$ positive). Overall, the NLPHL component was more frequently positive for EMA, CD75 and J-chain than the DLBCL component. In contrast, B cell markers, CD10 and $B C L 2$, were more frequently expressed and were expressed at higher levels in the $D L B C L$ component than in the NLPHL component. In the independent series of de novo DLBCL 4 cases could be identified with a growth pattern and immunophenotype that suggested that they had arisen secondarily from NLPHL.

Conclusions: The morphology and immunophenotype of DLBCL arisen from NLPHL is heterogeneous. Further characterization of the particular molecular features of this subgroup is warranted to be able to better identify these cases among conventional DLBCL.
\end{abstract}

Keywords: Nodular lymphocyte predominant Hodgkin lymphoma, Diffuse large B cell lymphoma, Transformation

\section{Background}

Nodular lymphocyte predominant Hodgkin lymphoma (NLPHL) is a rare subtype of Hodgkin lymphoma (HL), which accounts for approximately $5 \%$ of all cases [1] and generally presents with early clinical stages and an indolent clinical behavior [2,3]. Middle aged males account for $75 \%$ of cases [3]. Histologically, NLPHL typically consists of large nodules of reactive small B cells with a few intermingled tumor cells, the so called lymphocyte predominant or LP cells. Morphologic variants with a

\footnotetext{
* Correspondence: s.hartmann@em.uni-frankfurt.de

${ }^{\dagger}$ Equal contributors

${ }^{1}$ Dr. Senckenberg Institute of Pathology, Hospital of the Goethe University,

Theodor-Stern-Kai 7, Frankfurt am Main D- 60590, Germany

Full list of author information is available at the end of the article
}

diffuse pattern or an abundant reactive $\mathrm{T}$ cell infiltrate mimicking $\mathrm{T}$ cell/histiocyte rich $\mathrm{B}$ cell lymphoma (THRLBCL) have been described [4,5]. Gene expression profiling studies have identified only marginal differences between LP cells and tumor cells of THRLBCL [6,7]. In contrast to Hodgkin and Reed-Sternberg cells of classical HL, LP cells usually show a preserved or only partially downregulated $\mathrm{B}$ cell phenotype $[6,8]$. They typically exhibit constitutive NF-kappaB activity [6] and active JAK-STAT-signaling [9]. Recently, germline mutations of the NPAT gene have been identified as risk factor for NLPHL in the Finnish population [10] and there are reports about a high familial risk in first degree relatives of NLPHL patients $[11,12]$.

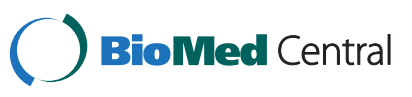


In the past 20 years, simultaneous or secondary transformation of NLPHL into diffuse large $B$ cell lymphoma (DLBCL) has been described in up to $30 \%$ of cases [13-18]. Several studies have suggested that these patients have a favorable outcome $[13,14,16,17,19]$. However, one study did not confirm this observation [15]. The male: female ratio for cases of NLPHL transformed into DLBCL was slightly higher than for primary NLPHL (77 - 81\%) [14-17]. The aim of the present study was to characterize morphology and immunophenotype of DLBCL simultaneously or sequentially derived from NLPHL in 33 cases. A second aim was the comparison of the immunophenotype observed in these particular cases with conventional DLBCL, in order to identify a marker panel, which allows to detect DLBCL, representing a putative transformation from NLPHL, in an independent series of DLBCL.

\section{Methods}

\section{Tissue samples}

A series of 33 consecutive cases of composite lymphoma of NLPHL and DLBCL were identified from the archives of the Dr. Senckenberg Institute of Pathology, Goethe University, Frankfurt am Main, Germany and the Department of Pathology, Tampere University Hospital, Tampere, Finland. Original diagnoses were made between 1987 and 2013. Original slides were complemented by additional stainings (see below). All diagnoses could be confirmed according to the WHO classification 2008 after joint review (S.H., M.E., M.V. and in part M.L.H.). In 26 cases both the NLPHL and DLBCL were present in the same biopsy, and in 7 cases, the DLBCL occurred sequentially after NLPHL. Two patients with simultaneous presentation of NLPHL and DLBCL had a previous history of NLPHL. NLPHL cases with transformation into pure THRLBCL were not included in the present study, since different mechanisms of transformation may be involved in these cases.

In a second step, 41 consecutive cases of male patients with DLBCL, diagnosed at the Pathology Department of Tampere University between 2003 and 2010, were selected from the archives and analyzed to identify cases representing a transformation from NLPHL ("LP-type DLBCL").

The study was approved by the local ethics committees of Frankfurt and Tampere University Hospital (ethics votes 120/13 from May, 23rd 2013 and 7085/05.01.00.06/ 2010 from October, 5th 2010).

\section{Immunohistochemistry}

All composite cases of NLPHL and DLBCL were investigated for CD20, CD79a, CD19, CD3, EMA, J-chain, CD75, CD10, BCL2, BCL6, CD30, CD15, MUM1, IgD, p-STAT6, JAK2 and EBER.
The cases of the second series of DLBCL were stained for CD20, CD3, CD10, BCL6, BCL2, CD75, EMA, J-chain and MUM1. In cases where transformation from NLPHL seemed likely, the specimens were additionally studied for IgD, CD30, CD15, and EBER. Twenty-eight cases each of DLBCL derived from NLPHL and conventional DLBCL were evaluated for the presence of follicular dendritic cells (FDCs) by CD21 and CD23.

Immunostainings were performed in the Pathology departments of Frankfurt and Tampere University using either an Alkaline Phosphatase-Real Detection Kit (DAKO, Glostrup, Denmark) or Peroxidase-EnVision Plus Kit (DAKO) as described previously [20]. The antibodies used, dilutions, and providers are listed in Additional file 1: Table S1. Antigen unmasking was performed for $3 \mathrm{~min}$ in a pressure cooker in TRIS-EDTA $\mathrm{pH}$ 8.0. All stainings were assessed using a multi-head microscope, and were scored as positive or weakly positive if $>50 \%$ of the tumor cells showed a reaction with the respective antibodies. Positivity perceivable at low magnification $(4 \times)$ was scored strongly positive, positivity only noticeable at higher magnification was scored weakly positive. Intensity of $\mathrm{B}$ cell markers (CD20, CD79a, CD19) was scored weakly positive if the expression intensity was weaker than in small reactive $B$ cells. In the composite cases it was also assessed, if the tumor cells in the DLBCL component

\section{Table 1 Clinical characteristics of patients studied}

\begin{tabular}{lll}
\hline & $\begin{array}{l}\text { NLPHL-DLBCL } \\
(\mathrm{n}=33)\end{array}$ & $\begin{array}{l}\text { Conventional } \\
\text { DLBCL }(\mathrm{n}=41)\end{array}$ \\
\hline $\begin{array}{l}\text { Patients with simultaneous } \\
\text { involvement by NLPHL and DLBCL }\end{array}$ & 26 & - \\
$\begin{array}{l}\text { Patients with sequential } \\
\text { involvement by NLPHL and DLBCL }\end{array}$ & 7 & - \\
Median patient age (range) & $50(19-78)$ & $69(19-93)$ \\
male gender (\%) & 85 & $100^{*}$ \\
Biopsy site & & \\
- axillary & $12(36 \%)$ & $4(10 \%)$ \\
- cervical/supraclavicular & $9(27 \%)$ & $26(63 \%)$ \\
- abdominal/mesenteric LN/bowel & $8(24 \%)$ & $5(12 \%)$ \\
- inguinal & $4(12 \%)$ & $1(2 \%)$ \\
- mediastinal/retroperitoneal & 0 & $3(7 \%)$ \\
- other & 0 & $2(5 \%)$ \\
Splenic involvement & $30 \%$ & $5 \%$ \\
Stage** & & $7(17 \%)$ \\
- I & $2(9 \%)$ & $12(29 \%)$ \\
- II & $4(18 \%)$ & $12(29 \%)$ \\
- III & $6(27 \%)$ & $10(24 \%)$ \\
- IV & $10(45 \%)$ & \\
\hline
\end{tabular}

*only male patients were selected.

${ }^{* *}$ Clinical stages were available in 22 of 33 NLPHL-DLBCL composite lymphomas. 
showed enhanced or attenuated expression compared with the LP cells in the NLPHL component.

\section{Results}

\section{Clinical and morphologic findings of NLPHL + DLBCL composite lymphomas}

Twenty-six patients presented with NLPHL and DLBCL simultaneously in the same lymph node. Seven patients developed sequential DLBCL secondary to the previous diagnosis of NLPHL with a median time to transformation of 8 years. The median patient age (50 years) did not differ between patients with simultaneous or sequential presentation of the disease. Detailed clinical characteristics are displayed in Table 1. In twenty patients, the treatment and follow up was known: $65 \%$ of the patients were treated by $\mathrm{R}-\mathrm{CHOP}, 10 \%$ received ABVD, $10 \%$ did not receive any treatment due to poor performance status. One patient received rituximab only, and two patients underwent autologous stem cell transplantation. The median follow up time in these 20 patients was 21 months (21.5 months for alive patients), and the estimated 8-year progression free survival (PFS) and overall survival (OS) rates were 69\% and $54 \%$, respectively. Patients with sequential transformation showed a non-significant trend towards worse overall and progression free survival compared to patients with simultaneous presentation of NLPHL and DLBCL (Additional file 2: Figure S1).

\section{Morphologic findings of NLPHL + DLBCL composite lymphomas}

The ratios of the NLPHL and DLBCL components were heterogeneous in the infiltrated tissue. In some cases, only a few nodules of NLPHL could be observed at the margins of the tissue effaced by the DLBCL. The NLPHL component showed a typical nodular pattern in 10 cases (pattern A according to Fan et al. [4]); whereas, 23 cases presented $\mathrm{T}$ cell rich and diffuse patterns (patterns non-A/B). DLBCL transformed from NLPHL consisted either of nodular, sharply demarcated, large cohesive sheets of blasts with few bystander cells (21 cases, Figure 1a and b) or of small sheets of blasts, with an abundant $\mathrm{T}$ cell and histiocyte infiltrate (12 cases, Figure $1 \mathrm{c}$ and $\mathrm{d}$ ). These latter cases were reminiscent of $\mathrm{T}$ cell/histiocyte rich large $\mathrm{B}$ cell lymphoma, but the tumor cell content was greater than $10 \%$ of the total infiltrate and the blasts formed small clusters. Whereas necrosis was never observed in NLPHL, four cases showed necrotic foci within the DLBCL component. In these areas, the blasts showed

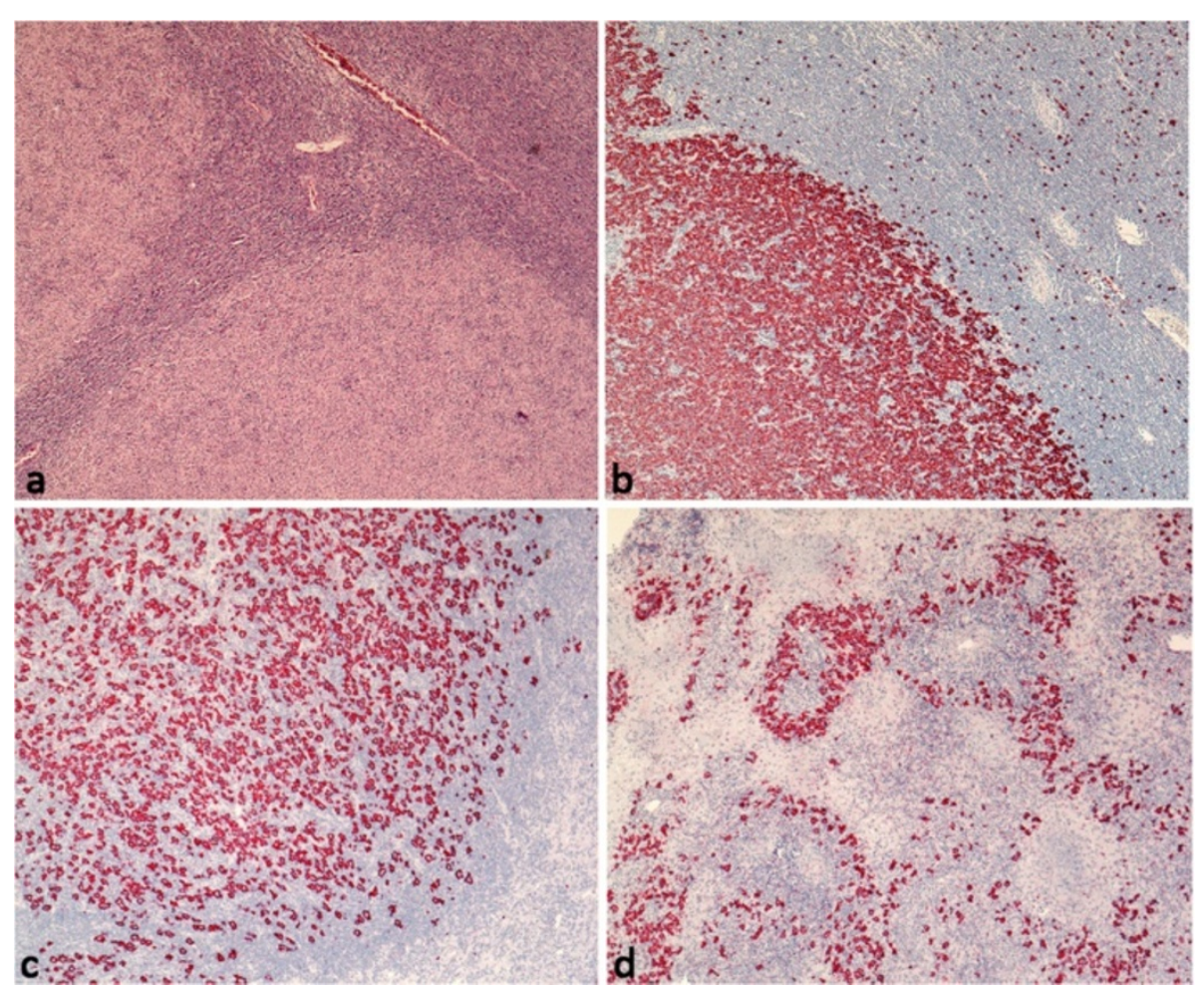

Figure 1 Typical infiltration patterns of "LP type" DLBCL in composite lymphomas. a. Sharply demarcated infiltrate of pale staining blasts, HE (40x). b. Sharply demarcated blast infiltrate, CD20 (40x). c. Sharply demarcated blast infiltrate with T cell and histiocyte rich microenvironment (CD20, 40X). d. DLBCL with abundant necrosis and blast infiltrate predominantly in perivascular localization (CD20, 40X). 
a predominant perivascular distribution (Figure 1d). In all cases the blasts exhibited large nuclei compared with common de novo DLBCL, and presented a broad, pale cytoplasm. The morphologies of the nuclei were variable (12 centroblastic polymorph, 11 multilobated, 6 anaplastic, 3 centroblastic monomorph, 1 immunoblastic).

\section{Immunophenotype of NLPHL + DLBCL composite lymphomas}

Immunostainings were scored positive, weakly positive, or negative in the tumor cells of both NLPHL and DLBCL components. The intensity of the staining of both components was compared and was also recorded if enhanced or reduced expression in the DLBCL component was observed (Table 2).

The immunophenotype of neoplastic cells in both the NLPHL part and the DLBCL components were largely consistent with the immunophenotype previously reported for LP cells [1]. However, 32 of 33 cases showed a difference in the immunophenotype or intensity between NLPHL and DLBCL in at least one staining. BCL6 and CD79a were expressed in the tumor cells of both components in all cases. CD75, EMA, and J-chain were expressed in most cases in the LP cells of NLPHL (97\%, 82\%, and $82 \%$ of the cases, respectively, Table 2, Figure 2) and in the tumor cells of the DLBCL component (94\%, 73\%, and 73\% of the cases, respectively). Although attenuation or loss of expression of EMA and J-chain was observed in the DLBCL component, these markers were significantly more frequently positive compared with conventional DLBCL $(\mathrm{p}<0.05$,
2-Tail Fisher's Exact Test, see below). MUM1 was weakly expressed as is typically observed in germinal center $\mathrm{B}$ cells [21] at approximately the same frequency in both the NLPHL and DLBCL components (63\% and 72\%). Surprisingly, B cell markers were more likely to exhibit enhanced expression in the DLBCL component: CD19 and CD79a were more strongly expressed in the DLBCL component compared to the LP cells in $66 \%$ and $33 \%$ of the cases, respectively (Table 2, Figure 3 ). The LP cells were negative or only weakly positive for BCL2 in $82 \%$. However, BCL2 and CD10 (Figure 2d) were upregulated in the DLBCL component in 38 and $33 \%$ of cases, respectively. JAK2, p-STAT6, CD30, CD15, and IgD were expressed in only a few cases of both DLBCL and NLPHL. There was no correlation between the JAK2- and p-STAT6positive cases. The four cases strongly expressing CD15 (>80\% of the tumor cells) in the DLBCL component were CD30-negative. All cases were negative for EBER.

\section{Independent series of conventional DLBCL}

In order to compare DLBCL transformed from NLPHL ("LP type" DLBCL) with conventional DLBCL and to identify more cases that may be derived from NLPHL, we evaluated an independent series of 41 DLBCL for their morphology and immunophenotype. Because of the high prevalence of males in the first series, we decided to investigate all males diagnosed with DLBCL at the Pathology Department of Tampere between 2003 and 2013. Clinical data are shown in Table 1. Because we had observed typical positivity for BCL6, CD75,

Table 2 Immunophenotype of composite lymphomas with NLPHL and DLBCL

\begin{tabular}{|c|c|c|c|c|c|c|}
\hline Immuno-staining & $\begin{array}{l}\text { DLBCL } \\
\text { component } \\
\text { positive }\end{array}$ & $\begin{array}{l}\text { LP cells } \\
\text { positive }\end{array}$ & $\begin{array}{l}\text { Reduced expression } \\
\text { in DLBCL component }\end{array}$ & $\begin{array}{l}\text { Enhanced } \\
\text { expression in DLBCL } \\
\text { component }\end{array}$ & $\begin{array}{l}\text { Identical expression in } \\
\text { DLBCL and NLPHL } \\
\text { component }\end{array}$ & $\begin{array}{l}\text { Identical expression in } \\
\text { DLBCL and NLPHL in } \\
\text { simultaneous cases }\end{array}$ \\
\hline $\mathrm{Bcl6}$ & $33 / 33(100 \%)$ & $33 / 33(100 \%)$ & $3 \%$ & $0 \%$ & $97 \%$ & $96 \%$ \\
\hline CD79a & $33 / 33(100 \%)$ & $33 / 33(100 \%)$ & $0 \%$ & $33 \%$ & $67 \%$ & $62 \%$ \\
\hline CD19 & $32 / 33(97 \%)$ & 25/32 (78\%) & $3 \%$ & $66 \%$ & $31 \%$ & $32 \%$ \\
\hline CD75 & $31 / 33(94 \%)$ & $32 / 33(97 \%)$ & $12 \%$ & $9 \%$ & $79 \%$ & $81 \%$ \\
\hline EMA & $24 / 33(73 \%)$ & $27 / 33(82 \%)$ & $18 \%$ & $6 \%$ & $76 \%$ & $85 \%$ \\
\hline J-chain & $24 / 33(73 \%)$ & 27/33 (82\%) & $27 \%$ & $3 \%$ & $70 \%$ & $77 \%$ \\
\hline $\mathrm{BCl} 2^{*}$ & $20 / 32(63 \%)$ & $27 / 33(82 \%)$ & $0 \%$ & $38 \%$ & $63 \%$ & $69 \%$ \\
\hline MUM1 & $21 / 33(63 \%)$ & $24 / 32(72 \%)$ & $13 \%$ & $13 \%$ & $75 \%$ & $77 \%$ \\
\hline JAK2 & $12 / 30(40 \%)$ & $4 / 27(15 \%)$ & $0 \%$ & $23 \%$ & $77 \%$ & $82 \%$ \\
\hline CD10 & $12 / 33(36 \%)$ & $2 / 33(6 \%)$ & $0 \%$ & $33 \%$ & $67 \%$ & $69 \%$ \\
\hline p-STAT6 & $9 / 30(30 \%)$ & $8 / 26(31 \%)$ & $9 \%$ & $5 \%$ & $86 \%$ & $89 \%$ \\
\hline CD30 & 7/33 (21\%) & $7 / 33$ (21\%) & $6 \%$ & $6 \%$ & $88 \%$ & $92 \%$ \\
\hline CD15 & $4 / 33(12 \%)$ & $2 / 33(6 \%)$ & $0 \%$ & $12 \%$ & $88 \%$ & $85 \%$ \\
\hline $\lg D$ & 4/33 (12\%) & $5 / 33(15 \%)$ & $3 \%$ & $0 \%$ & $97 \%$ & $96 \%$ \\
\hline
\end{tabular}

Immunohistochemical stainings were assessed separately in the NLPHL and DLBCL component. Stainings were also assessed if there was an enhanced or decreased staining intensity in the DLBCL component compared to the LP cells in NLPHL.

*Since BCL2 was usually negative or weakly positive in LP cells, the frequency of negative or weakly positive cases is given. 


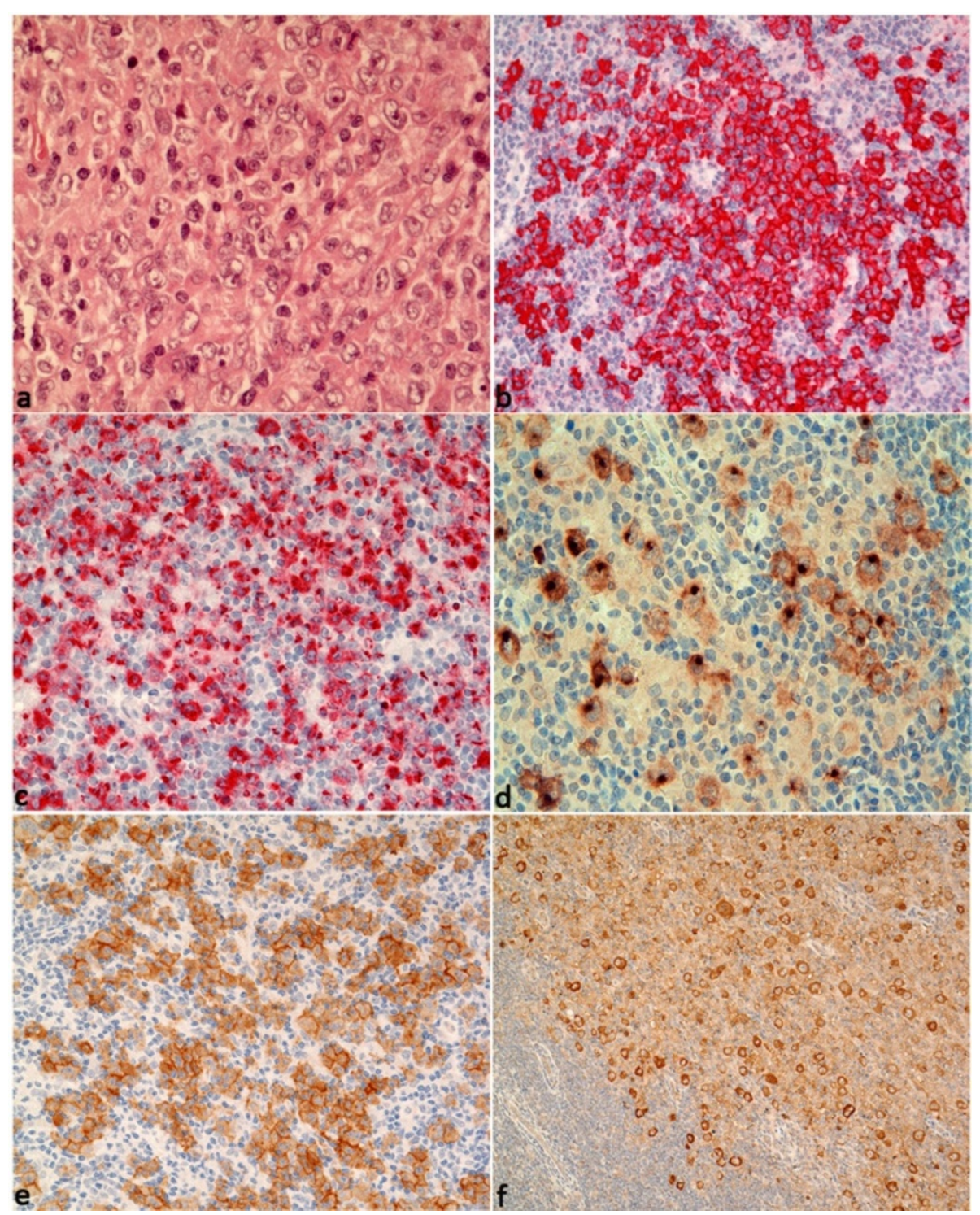

Figure 2 Typical and special features of "LP type" DLBCL in composite lymphomas. a. Typical blast infiltrate with broad pale cytoplasm and lobulated LP cell-like nuclei $(\mathrm{HE}, 400 \times)$. b. Blast infiltrate strongly expressing EMA as observed in 73\% of "LP type" DLBCL (EMA immunostaining, 200x). c. Expression of CD15 in the cytoplasm and Golgi field in 4 of 33 "LP type" DLBCL (CD15 immunostaining, 200X). d. Expression of CD10 in the cytoplasm and Golgi in 36\% of "LP type" DLBCL (CD10 immunostaining, 400x). e. IgD expression in blasts observed in 4 of 33 "LP type" DLBCL (IgD immunostaining, 200x). f. JAK2 expression found in 43\% of "LP type" DLBCL (JAK2 immunostaining, 100X).

EMA, J-chain, and weak MUM1 expression as well as negativity or weak positivity for BCL2 in "LP type" DLBCL, all cases of the second series were stained for theses antigens and were additionally evaluated for the presence of FDCs.

All cases were positive for $\mathrm{CD} 20$, and the majority of cases were positive for BCL6, CD75, and MUM1 $(83 \%, 85 \%$, and $83 \%$, respectively, Table 3$)$. FDCs were rarely observed in both "LP type" and conventional DLBCL (Table 3). However, EMA (27\%) and J-chain (22\%) were significantly less frequently positive $(\mathrm{p}<0.05,2$-Tail
Fisher's Exact Test) in conventional DLBCL compared to "LP type" DLBCL. Only three cases expressed both EMA and J-chain (see below). Likewise, a negative or weakly positive BCL2 staining was only observed in $32 \%$ of cases of conventional DLBCL in the second series and was significantly less frequently observed than in "LP type" DLBCL ( $<<0.05,2$-Tail Fisher's Exact Test). Therefore we selected all cases with a nodular, sheet-like growth pattern or a histiocyte rich microenvironment and expression of BCL6, CD75, and J-chain and (or) EMA. Five cases meeting these criteria, including the three EMA-J-chain 


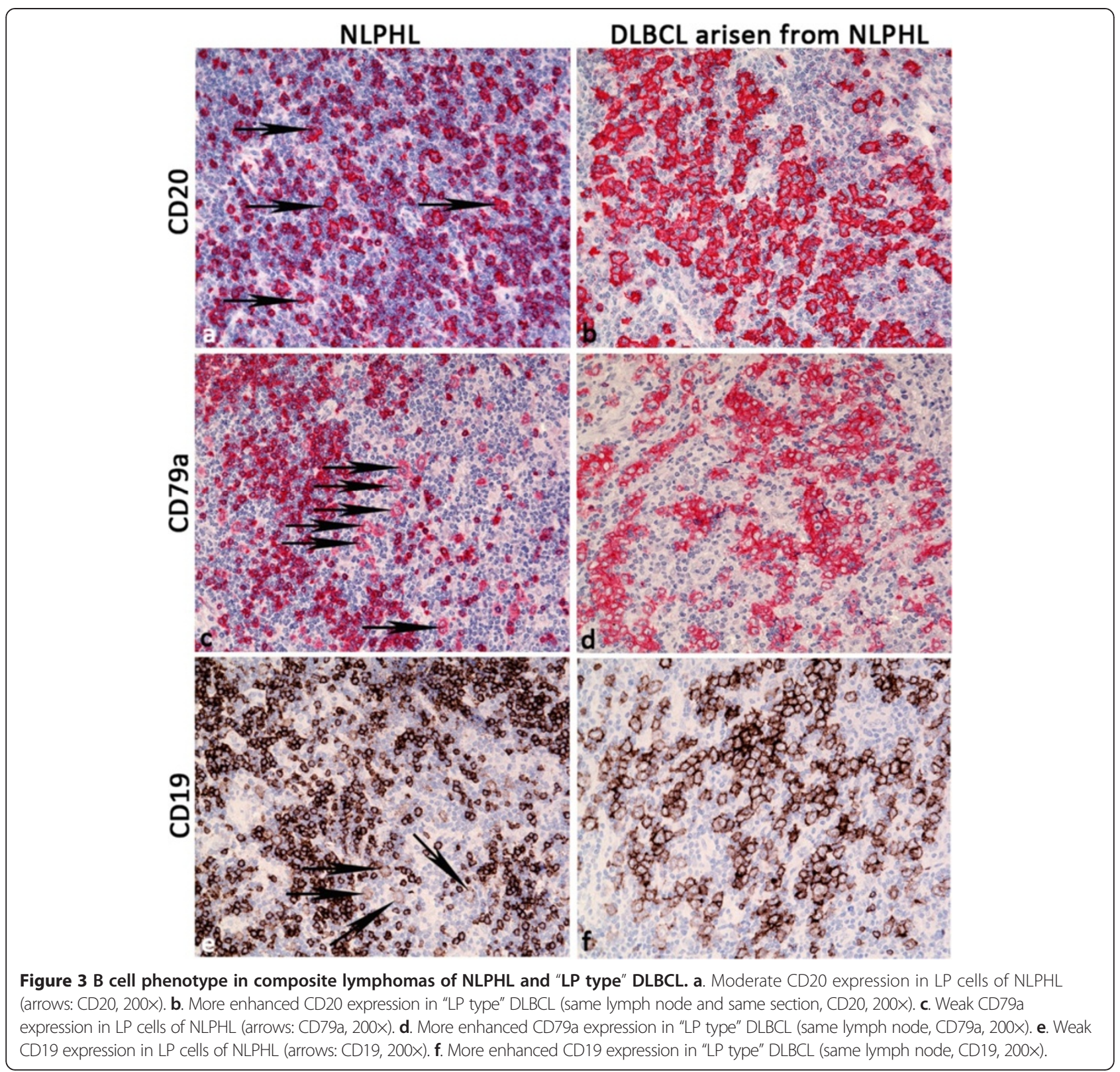

double positive cases, were further evaluated for CD30, CD15, EBER, IgD, and CD19. One of these sheet-like growing DLBCL, which was positive for BCL6, CD75, $\mathrm{J}$-chain, and EMA and involved the parotid gland of a 36 year-old male, could be excluded as a transformed marginal zone lymphoma: after closer work-up of this case, a low-grade lymphoma component with a typical follicular colonization pattern was discovered in an additional tissue block. Finally, four "LP type" DLBCL were identified among the 41 DLBCL cases (10\%, Figure 4). All four cases were positive for BCL6, CD75, and EMA. Three cases were additionally positive for J-chain and weakly positive or negative for BCL2. One case was positive for IgD, one for CD10, and one for CD30. All four cases were negative for EBER and CD15.

\section{Clinical features of four DLBCL cases with putative} derivation from NLPHL

The median age of these patients was 31.5 years. The localization of the biopsies were cervical (in two cases), axillary and mesenteric. One patient was diagnosed in stage II, one in stage III, and two in stage IV. Three of four patients presented splenic involvement, and two of these additionally presented liver involvement. Two patients achieved complete remission after R-CHOP/R-CHOEP, and one patient achieved remission after $\mathrm{R}-\mathrm{CHOP}$ and 
Table 3 Immunophenotype of "LP type" DLBCL (transformed from NLPHL) compared to conventional DLBCL

\begin{tabular}{|c|c|c|}
\hline Staining pattern typically observed in DLBCL transformed from NLPHL & "LP type" DLBCL $(n=33)$ & Conventional DLBCL $(n=41)$ \\
\hline Bcl-6 strongly positive & $33(100 \%)$ & $34(83 \%)$ \\
\hline CD10 weakly or strongly positive & $12(36 \%)$ & $15(37 \%)$ \\
\hline CD75 weakly or strongly positive & $31(94 \%)$ & $35(85 \%)$ \\
\hline EMA weakly or strongly positive & $24(73 \%)^{*}$ & $11(27 \%)^{*}$ \\
\hline MUM1 weakly or strongly positive & $21(63 \%)$ & $34(83 \%)$ \\
\hline J-chain weakly or strongly positive & $24(73 \%)^{*}$ & $9(22 \%)^{*}$ \\
\hline Bcl2 weakly positive or negative & $20(63 \%)^{*}$ & $13(32 \%)^{*}$ \\
\hline CD21-positive follicular dendritic cells & $1 / 28(4 \%)$ & $5 / 28(18 \%)$ \\
\hline CD23-positive follicular dendritic cells & $0 / 28(0 \%)$ & $5 / 28(18 \%)$ \\
\hline
\end{tabular}

*Staining patterns which were significantly more frequently observed in "LP type" DLBCL compared to conventional DLBCL are printed in bold $(p<0.05,2$-Tail Fisher's Exact Test).

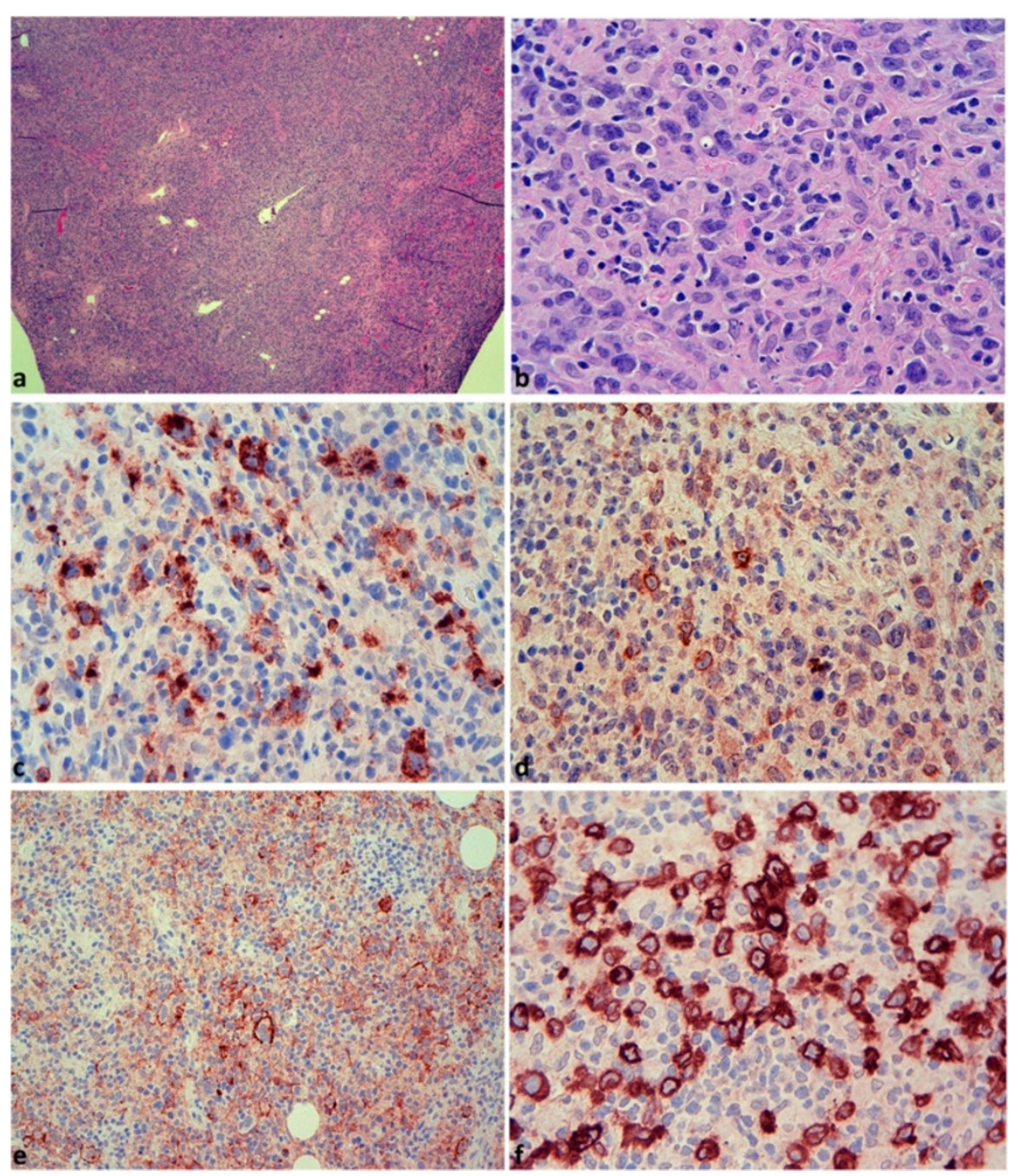

Figure 4 "LP type" DLBCL, presumably transformed from NLPHL. Cervical lymph node biopsy of one of the patients presenting with "LP type" DLBCL. a. HE, 40x. The lymph node architecture is effaced with open sinuses. b. HE, 400x. Higher magnification reveals a blast infiltrate with a broad, pale cytoplasm and large numbers of histiocytes. c. Blasts stain partly positive for CD75 (400x). d. A subset of blasts is positive for J-chain $(400 \times)$. e. The infiltrate weakly expresses EMA (200x). f. IgD is strongly expressed in the blast population (400x). 
subsequent autologous stem cell transplant. One patient received DHAP but died few months after diagnosis.

\section{Discussion}

In the present study we investigated 33 patients with NLPHL and transformation into DLBCL. Although 26 of 33 patients in the present study showed a simultaneous presentation of NLPHL and DLBCL, the clinical data match well with previous studies of secondary transformations of NLPHL into DLBCL $[16,17]$. Histopathologic variant patterns (“Non-A/B") as described by Fan et al. [4] were seen in the NLPHL component in $70 \%$ of composite cases investigated in the present study. Histopathologic variants have been associated with advanced stage and an increased risk of relapse [4,5,22] and the high frequency in the present study likely points to an increased risk of transformation into DLBCL in these patients.

In the present study, we observed in most composite NLPHL-DLBCL cases, a particular pattern of infiltration with a sharply demarcated sheet-like blast expansion or with a relatively high number of histiocytes admixed with the DLBCL component. The morphology of the nuclei was variable, as previously observed [14]. The most common immunophenotype, differing from conventional DLBCL, was coexpression of EMA and J-chain. However, this immunophenotype was not specific. EMA expression in DLBCL derived from NLPHL was also observed in one previous study [14]. Another remarkable observation was the upregulation of $\mathrm{B}$ cell markers as well as BCL2 in the DLBCL component compared to the NLPHL component. Possibly, the slight downregulation of $\mathrm{B}$ cell receptor signaling observed in the LP cells of NLPHL $[6,8]$ is substituted by stimulation from rosetting follicular $\mathrm{T}$ helper cells. Since T cell rosetting was never observed in the DLBCL component, these tumor cells must have acquired additional properties to ensure their survival. One of these features may represent enhanced tonic active B cell receptor signaling [23-25] or the upregulation of BCL2 anti-apoptotic protein [26,27]. The increased number of tumor cells in "LP type" DLBCL compared to the NLPHL component may result from enhanced anti-apoptotic properties resulting from BCL2 expression. In the present series, p-STAT6 and JAK2 were expressed in both components less frequently than previously observed [9]. Possibly, SOCS1-mutated NLPHL cases with active JAK-STAT-signaling are less likely to transform into DLBCL and may, therefore, have a better prognosis similar to DLBCL with truncating SOCS1 mutations [28]. We also observed upregulation of CD15 and CD10 in some cases of "LP type" DLBCL. CD15 expression has been described in a subset of NLPHL-DLBCL composite lymphomas [14], whereas CD15 expression in NLPHL generally is a rare phenomenon
$[3,29,30]$. Upregulation of these markers may be associated with activation of the tumor cells as observed for CD30 expression [31-33].

Since we also identified four cases with a typical "LP type" infiltration pattern and immunophenotype in a series of conventional DLBCL, we hypothesize that a series of conventional DLBCL cases will include cases with transformation from NLPHL, particularly if diagnoses are made on small core biopsies. Since some of the composite cases showed a downregulation of J-chain and EMA as well as an upregulation of CD10 and BCL2 in the DLBCL component, these cases may be difficult to identify applying current histopathologic methods if only the DLBCL component is sampled. Furthermore, the immunohistochemical stainings, observed to be frequently positive in the present study, were not specific, as was demonstrated in the case of transformed marginal zone lymphoma, which was positive for both EMA and J-chain.

\section{Conclusions}

In the present study we observed a heterogeneous immunophenotype of DLBCL derived from NLPHL, which may reflect different mechanisms of transformation. This fact makes these cases difficult to recognize, if the NLPHL component is not sampled. Men with sharply demarcated blast infiltrates with EMA- and/or J-chain expression and abdominal, splenic, or axillary localization are more likely to have "LP type" DLBCL. However, it is important to state, that by applying current immunohistochemical markers, there is no way to specifically recognize these cases unless the coexisting NLPHL component can be identified. Therefore, further characterization of the particular clinical and molecular features of "LP type" DLBCL among conventional DLBCL is warranted, and may lead to identification of better diagnostic markers.

\section{Additional files}

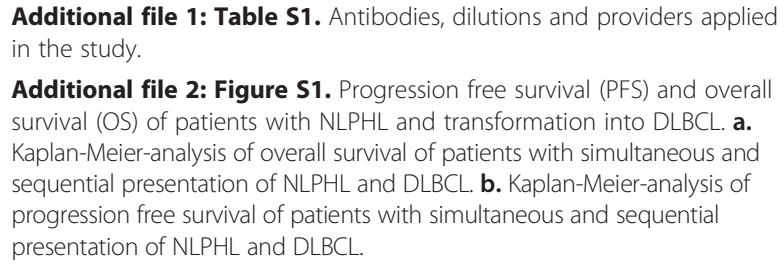

Additional file 1: Table S1. Antibodies, dilutions and providers applied in the study.

Additional file 2: Figure S1. Progression free survival (PFS) and overall survival (OS) of patients with NLPHL and transformation into DLBCL. a. Kaplan-Meier-analysis of overall survival of patients with simultaneous and sequential presentation of NLPHL and DLBCL. b. Kaplan-Meier-analysis of progression free survival of patients with simultaneous and sequential presentation of NLPHL and DLBCL.

Competing interests

The authors report no potential conflict of interest.

\section{Authors' contributions}

$\mathrm{SH}$ and MV: design of the study, acquired and analysed data, drafted the manuscript; ME, UB, TL, PK: acquired and analysed data; CD: biostatistical analysis; MLH: design of the study and drafted the manuscript. All authors read and approved the final manuscript. 


\section{Acknowledgments}

The authors thank Prof. Timo Paavonen and the University of Tampere for providing facilities and materials essential for this study. We thank Yvonne Michel, Ralf Lieberz, and Sabine Albrecht for excellent technical assistance. The authors thank Prof. Ralf Küppers, Essen, for helpful discussions. This project was funded by the Deutsche Forschungsgemeinschaft (DFG) grant HA 6145/1-1.

\section{Author details}

${ }^{1}$ Dr. Senckenberg Institute of Pathology, Hospital of the Goethe University, Theodor-Stern-Kai 7, Frankfurt am Main D- 60590, Germany. ${ }^{2}$ Department of Pathology, Tampere University Hospital and University of Tampere, Tampere 33520, Finland. ${ }^{3}$ Department of Oncology, Tampere University Hospital, Tampere 33520, Finland. ${ }^{4}$ Department of Internal Medicine 2, Hospital of the J. W. Goethe University, Frankfurt am Main, Germany.

Received: 2 March 2014 Accepted: 9 May 2014

Published: 13 May 2014

\section{References}

1. Swerdlow SH: International Agency for Research on Cancer. World Health Organization: WHO classification of tumours of haematopoietic and lymphoid tissues, 4th edn. Lyon, France: International Agency for Research on Cancer; 2008.

2. Sextro M, Diehl V, Franklin J, Hansmann ML, Anagnostopoulos I, Marafioti T, Stein H: Lymphocyte predominant Hodgkin's disease-a workshop report. European Task Force on Lymphoma. Ann Oncol 1996, 4(7 Suppl):61-65.

3. Anagnostopoulos I, Hansmann ML, Franssila K, Harris M, Harris NL, Jaffe ES, Han J, Van Krieken JM, Poppema S, Marafioti T, Franklin J, Sextro M, Diehl V, Stein H: European Task Force on Lymphoma project on lymphocyte predominance Hodgkin disease: histologic and immunohistologic analysis of submitted cases reveals 2 types of Hodgkin disease with a nodular growth pattern and abundant lymphocytes. Blood 2000, 96(5):1889-1899.

4. Fan Z, Natkunam Y, Bair E, Tibshirani R, Warnke RA: Characterization of variant patterns of nodular lymphocyte predominant hodgkin lymphoma with immunohistologic and clinical correlation. Am J Surg Pathol 2003, 27(10):1346-1356.

5. Boudova L, Torlakovic E, Delabie J, Reimer P, Pfistner B, Wiedenmann S, DiehI V, Muller-Hermelink HK, Rudiger T: Nodular lymphocyte-predominant Hodgkin lymphoma with nodules resembling T-cell/histiocyte-rich B-cell lymphoma: differential diagnosis between nodular lymphocyte-predominant Hodgkin lymphoma and T-cell/histiocyte-rich B-cell lymphoma. Blood 2003, 102(10):3753-3758.

6. Brune V, Tiacci E, Pfeil I, Doring C, Eckerle S, Van Noesel CJ, Klapper W, Falini B, Von Heydebreck A, Metzler D, Brauninger A, Hansmann ML, Kuppers R: Origin and pathogenesis of nodular lymphocyte-predominant Hodgkin lymphoma as revealed by global gene expression analysis. J Exp Med 2008, 205(10):2251-2268.

7. Hartmann S, Doring C, Jakobus C, Rengstl B, Newrzela S, Tousseyn T, Sagaert X, Ponzoni M, Facchetti F, De Wolf-Peeters C, Steidl C, Gascoyne R, Kuppers R, Hansmann ML: Nodular lymphocyte predominant hodgkin lymphoma and T cell/histiocyte rich large B cell lymphoma - endpoints of a spectrum of one disease? PLoS One 2013, 8(11):e78812.

8. Tedoldi S, Mottok A, Ying J, Paterson JC, Cui Y, Facchetti F, Van Krieken JH, Ponzoni M, Ozkal S, Masir N, Natkunam Y, Pileri S, Hansmann ML, Mason D, Tao Q, Marafioti T: Selective loss of B-cell phenotype in lymphocyte predominant Hodgkin lymphoma. J Pathol 2007, 213(4):429-440.

9. Mottok A, Renne C, Willenbrock K, Hansmann ML, Brauninger A: Somatic hypermutation of SOCS1 in lymphocyte-predominant Hodgkin lymphoma is accompanied by high JAK2 expression and activation of STAT6. Blood 2007, 110(9):3387-3390.

10. Saarinen S, Aavikko M, Aittomaki K, Launonen V, Lehtonen R, Franssila K, Lehtonen HJ, Kaasinen E, Broderick P, Tarkkanen J, Bain BJ, Bauduer F, Unal A, Swerdlow AJ, Cooke R, Makinen MJ, Houlston R, Vahteristo P, Aaltonen LA: Exome sequencing reveals germline NPAT mutation as a candidate risk factor for Hodgkin lymphoma. Blood 2011, 118(3):493-498.

11. Saarinen S, Pukkala E, Vahteristo P, Makinen MJ, Franssila K, Aaltonen LA: High familial risk in nodular lymphocyte-predominant Hodgkin lymphoma. J Clin Oncol 2013, 31(7):938-943.
12. Merli M, Maffioli M, Ferrario A, Passamonti F: Looking for familial nodular lymphocyte-predominant Hodgkin lymphoma. Am J Hematol 2013, 88(8):719-720

13. Sundeen JT, Cossman J, Jaffe ES: Lymphocyte predominant Hodgkin's disease nodular subtype with coexistent "large cell lymphoma". Histological progression or composite malignancy? Am J Surg Pathol 1988, 12(8):599-606.

14. Hansmann ML, Stein H, Fellbaum C, Hui PK, Parwaresch MR, Lennert K: Nodular paragranuloma can transform into high-grade malignant lymphoma of B type. Hum Pathol 1989, 20(12):1169-1175.

15. Huang JZ, Weisenburger DD, Vose JM, Greiner TC, Aoun P, Chan WC, Lynch $J C$, Bierman PJ, Armitage JO: Diffuse large B-cell lymphoma arising in nodular lymphocyte predominant Hodgkin lymphoma: a report of 21 cases from the Nebraska Lymphoma Study Group. Leuk Lymphoma 2004, 45(8):1551-1557.

16. Al-Mansour M, Connors JM, Gascoyne RD, Skinnider B, Savage KJ: Transformation to aggressive lymphoma in nodular lymphocyte-predominant Hodgkin's lymphoma. J Clin Oncol 2010, 28(5):793-799.

17. Biasoli I, Stamatoullas A, Meignin V, Delmer A, Reman O, Morschhauser F, Coiffier B, Bosly A, Divine M, Brice P: Nodular, lymphocyte-predominant Hodgkin lymphoma: a long-term study and analysis of transformation to diffuse large B-cell lymphoma in a cohort of 164 patients from the Adult Lymphoma Study Group. Cancer 2010, 116(3):631-639.

18. Jackson C, Sirohi B, Cunningham D, Horwich A, Thomas K, Wotherspoon A Lymphocyte-predominant Hodgkin lymphoma-clinical features and treatment outcomes from a 30-year experience. Ann Oncol 2010, 21(10):2061-2068.

19. Cotta CV, Coleman JF, Li S, Hsi ED: Nodular lymphocyte predominant Hodgkin lymphoma and diffuse large B-cell lymphoma: a study of six cases concurrently involving the same site. Histopathology 2011, 59(6):1194-1203.

20. Renné C, Willenbrock K, Küppers R, Hansmann ML, Bräuninger A: Autocrine- and paracrine-activated receptor tyrosine kinases in classic Hodgkin lymphoma. Blood 2005, 105(10):4051-4059.

21. Ochiai K, Maienschein-Cline M, Simonetti G, Chen J, Rosenthal R, Brink R, Chong AS, Klein U, Dinner AR, Singh H, Sciammas R: Transcriptional Regulation of Germinal Center B and Plasma Cell Fates by Dynamical Control of IRF4. Immunity 2013, 38(5):918-929.

22. Hartmann S, Eichenauer DA, Plutschow A, Mottok A, Bob R, Koch K, Bernd HW, Cogliatti S, Hummel M, Feller AC, Ott G, Moller P, Rosenwald A, Stein H, Hansmann ML, Engert A, Klapper W: The prognostic impact of variant histology in nodular lymphocyte-predominant Hodgkin lymphoma: a report from the German Hodgkin Study Group (GHSG). Blood 2013, 122(26):4246-4252.

23. Lam KP, Kühn R, Rajewsky K: In vivo ablation of surface immunoglobulin on mature $B$ cells by inducible gene targeting results in rapid cell death. Cell 1997, 90:1073-1083.

24. Kraus M, Alimzhanov MB, Rajewsky N, Rajewsky K: Survival of resting mature $B$ lymphocytes depends on $B C R$ signaling via the Igalpha/beta heterodimer. Cell 2004, 117:787-800.

25. Young RM, Staudt LM: Targeting pathological B cell receptor signalling in lymphoid malignancies. Nat Rev Drug Discov 2013, 12(3):229-243.

26. Alnemri ES, Robertson NM, Fernandes TF, Croce CM, Litwack G: Overexpressed full-length human BCL2 extends the survival of baculovirus-infected Sf9 insect cells. Proc Natl Acad Sci U S A 1992, 89(16):7295-7299.

27. Hockenbery DM, Zutter M, Hickey W, Nahm M, Korsmeyer SJ: BCL2 protein is topographically restricted in tissues characterized by apoptotic cell death. Proc Natl Acad Sci U S A 1991, 88(16):6961-6965.

28. Schif B, Lennerz JK, Kohler CW, Bentink S, Kreuz M, Melzner I, Ritz O, Trumper L, Loeffler M, Spang R, Moller P: SOCS1 mutation subtypes predict divergent outcomes in diffuse large B-Cell lymphoma (DLBCL) patients. Oncotarget 2013, 4(1):35-47.

29. Venkataraman G, Raffeld M, Pittaluga S, Jaffe ES: CD15-expressing nodular lymphocyte-predominant Hodgkin lymphoma. Histopathology 2011, 58(5):803-805.

30. Huppmann AR, Nicolae A, Slack GW, Pittaluga S, Davies-Hill T, Ferry JA, Harris NL, Jaffe ES, Hasserjian RP: EBV May Be Expressed in the LP Cells of Nodular Lymphocyte-predominant Hodgkin Lymphoma (NLPHL) in Both Children and Adults. Am J Surg Pathol 2014, 38(3):316-324.

31. Segal GH, Kjeldsberg CR, Smith GP, Perkins SL: CD30 antigen expression in florid immunoblastic proliferations. A clinicopathologic study of 14 cases. Am J Clin Pathol 1994, 102(3):292-298. 
32. Engels EA, Savoldo B, Pfeiffer RM, Costello R, Zingone A, Heslop HE, Landgren O: Plasma markers of B-cell activation and clonality in pediatric liver and hematopoietic stem cell transplant recipients. Transplantation 2013, 95(3):519-526.

33. Guo Y, Sun X, Shibata K, Yamada H, Muta H, Podack ER, Yoshikai Y: CD30 is required for activation of a unique subset of interleukin-17A-producing gammadelta $\mathrm{T}$ cells in innate immunity against Mycobacterium bovis Bacillus Calmette-Guerin infection. Infect Immun 2013, 81(10):3923-3934.

doi:10.1186/1471-2407-14-332

Cite this article as: Hartmann et al:: Diffuse large B cell lymphoma derived from nodular lymphocyte predominant Hodgkin lymphoma presents with variable histopathology. BMC Cancer 2014 14:332.

\section{Submit your next manuscript to BioMed Central and take full advantage of:}

- Convenient online submission

- Thorough peer review

- No space constraints or color figure charges

- Immediate publication on acceptance

- Inclusion in PubMed, CAS, Scopus and Google Scholar

- Research which is freely available for redistribution 